\title{
Risk Factors of Musculoskeletal Problems among Dental Professionals in a Dental Institute: A Cross-sectional Survey
}

\author{
Sagar J Shah ${ }^{1}$, Shrushti Shah ${ }^{2}$, Mahesh R Khairnar ${ }^{3}$, Rohit Dhole ${ }^{4}$, Umesh Wadgave $^{5}$, Amol Karagir $^{6}$, Swarali Shah $^{7}$
}

\begin{abstract}
Aim: To determine the risk factors and prevalence of various musculoskeletal disorders (MSDs) among dental professionals.

Materials and methods: A cross-sectional survey was carried out on a sample of 225 dental professionals by administering a structured questionnaire. The data collected were analyzed using descriptive statistics and binary logistic regression method.

Results: A high proportion of dental professionals reported MSDs at one or the other body regions, with neck being the most affected area (48.9\%) followed by lower back (46.2\%) and shoulder (45.8\%). Working in same position or awkward/cramped position, bending or twisting neck or back while working, etc. were some of the self-reported job risk factors among dental professionals. Females showed significantly increased risk of developing MSDs $(\mathrm{OR}=1.53)$ as compared to males. Non-vegetarian diet, lack of physical activity, excess daily working hours were other predictors for MSD.

Conclusion: Prevalence of MSD was high among dental professionals in the present study. Gender, diet, physical activity, working hours were found to be related with musculoskeletal pain. This calls for appropriate educational measures in ergonomics and identifying work-related and non-work-related risk factors to reduce the occurrence of MSD among dental professionals.

Clinical significance: This article provides insights in understanding risks factors and possible approaches to reduce MSDs in workplace.

Keywords: Dentists, Musculoskeletal symptoms, Occupational health hazards, Prevalence.

World Journal of Dentistry (2022): 10.5005/jp-journals-10015-1895
\end{abstract}

\section{INTRODUCTION}

As per the World Health Organization (WHO), musculoskeletal disorders (MSDs) are called work-related when the "working activities and conditions significantly induce and exacerbate them."1 MSDs are widespread and have a huge impact in the modern society. ${ }^{2}$ MSDs are common in several workplaces and it is considered as the second most common workplace hazard after the respiratory diseases. ${ }^{3} \mathrm{MSD}$ are notoriously known to cause physical as well as financial morbidity in the Indian subcontinent annually incurring upto $40 \%$ of all the costs of work-related injuries. ${ }^{2}$ Health care profession is known to be at a high risk for Work-related Musculoskeletal Disorders (WMSDs). It is estimated that almost one-third of all cases of sick leave among healthcare workers are related to MSDs. ${ }^{2}$ MSDs have a high prevalence rate of $60-90 \%$ in dental professionals in India due to various factors like prolonged static posture, long operating periods, handling of delicate instruments with significant force, etc. ${ }^{4}$ Commonly arising complaints reported in previous studies are back, neck, shoulder and wrist/ thumb problems. ${ }^{2,3,5,6}$ Long-term usage of high frequency vibrational instruments is also known to cause minor hand neuropathy. ${ }^{5,7}$

Ergonomics is derived from Greek Word Ergo means work and Nomos means natural laws. Ergonomics therefore is defined as "an applied science concerned with designing and arranging things people use so that the people and things interact most efficiently and safely. ${ }^{8}$ Dentists have to retain prolong static postures, and perform continuous neck, arms, shoulder and hand movements either in sitting or standing position which may result in discomfort in various body parts. If these repeated discomforts are neglected, they are likely to cause long-term musculoskeletal as well as psychological problems leading to decline in the performance and productivity. ${ }^{9-11}$ Thus, ergonomics is of paramount importance
${ }^{1}$ Department of Conservative Dentistry and Endodontics, Terna Dental College and Hospital, Navi Mumbai, Maharashtra, India

${ }^{2}$ Department of Public Health Dentistry, Bharati Vidyapeeth (Deemed to be University) Dental College and Hospital, Sangli, Maharashtra, India

${ }^{3}$ Public Health Dentistry, Faculty of Dental Sciences, IMS, Banaras Hindu University, Varanasi, Uttar Pradesh, India

${ }^{4}$ Department of Prosthodontics, Bharati Vidyapeeth (Deemed to be University) Dental College and Hospital, Sangli, Maharashtra, India

${ }^{5}$ Department of Public Health Dentistry, ESIC Dental College, Kalburgi, Karnataka, India

${ }^{6}$ Department of Oral Medicine and Radiology, Bharati Vidyapeeth (Deemed to be University) Dental College and Hospital, Sangli, Maharashtra, India

${ }^{7}$ Department of Pedodontics, Bharati Vidyapeeth (Deemed to be University) Dental College and Hospital, Sangli, Maharashtra, India

Corresponding Author: Mahesh R Khairnar, Public Health Dentistry, Faculty of Dental Sciences, IMS, Banaras Hindu University, Varanasi, Uttar Pradesh, India, Phone: +91 7045653288, e-mail:kmahesh222@gmail.com How to cite this article: Shah SJ, Shah S, Khairnar MR, et al. Risk Factors of Musculoskeletal Problems among Dental Professionals in a Dental Institute: A Cross-sectional Survey. World J Dent 2022;13(1):35-39.

Source of support: Nil

Conflict of interest: None

to maximize operators capabilities and at the same time ensure maximum operator safety.

Hence, the present study was conducted to determine the prevalence and identify the risk factors of MSD among dental healthcare professionals in a dental institute in Maharashtra, India. 


\section{Materials and Methods}

This cross-sectional survey was carried out on a convenient sample of 225 dental professionals from a dental institute in India, Sangli over a period of two months in August and September 2018. The study proposal was approved by Institutional Ethical Committee. All the interns, postgraduate students, BDS and MDS faculty members were well informed about the study and its objectives. Those who were willing to participate, after giving their consent, were included in the study.

The data was collected using self-administered questionnaire employed by Yasobant et al. in a previous research which was modified for the present study. ${ }^{2}$ The questionnaire consisted three sections, Section A included demographic details of the participants, medical history, diet pattern and details about lifestyle related factors; Section B included a rating scale to identify job risk factors based on participant perceptions about various conditions and tasks that may contribute to the development of WMSDs, by a scoring method using an ordinal scale of $0-10$; Section $C$ consisted of the Nordic Musculoskeletal Questionnaire (NMQ), which is a standardized screening and surveillance tool to find out the body regions affected by musculoskeletal symptoms. The questionnaire was presented before a group of experts in dentistry and necessary changes were made. This revised questionnaire was further administered on two different occasions to a group of 15 participants who were not a part of main study to check test-retest reliability. The value of Kappa coefficient was 0.78 which shows good reliability. Each participant in the main study was given sufficient time to fill the questionnaire.

\section{Statistical Analysis}

Data was collected, compiled, and analyzed using the Statistical Package for the Social Sciences (SPSS, IBM Corporation, Armonk, NY, USA) version 19. $p \leq 0.05$ was considered to be statistically significant. Descriptive statistics (mean and frequency distribution) were employed to describe the sociodemographic characteristics of participants. Frequency distribution method was used to report the self-reported job risk factors and prevalence of pain or discomfort in different body parts. The association of different demographic and work related variables with musculoskeletal symptoms was tested using regression method.

\section{Results}

Study population comprised of Interns [ $n=101$ (44.9\%)], postgraduate students [(PG students $n=80(35.6 \%)$, BDS faculty members $[n=8(3.6 \%)]$ and MDS faculty members $[n=36(16 \%)]$ (Table 1). Mean age, mean body mass index (BMI) and no. of working hours were 26.51 years, $23.61 \mathrm{~kg} / \mathrm{m}^{2}$ and 7.83 hours, respectively. Study population consisted of $37.3 \%$ males and $62.7 \%$ females. Majority of study participants (70.7\%) were non-vegetarian. $68.4 \%$ of the participants were involved in regular physical activity like sports, yoga, exercise, etc. Negligible proportions of participants were smokers (3.1\%) and alcoholics (5.3\%) (Table 1).

Working in awkward and cramped positions (45.8\%), bending or twisting your back in an awkward way (43.6\%), working in same position (38.9\%), performing manual techniques such as hand scaling, use of hand files during root canal therapy (35.8\%) and performing same task over and over again (33.3\%) were major job risk factors reported (Table 2 ).

About 78\% participants reported musculoskeletal symptoms in different body parts in last 12 months. Participants mostly suffered
Table 1: Details of demographic variables of study participants

\begin{tabular}{|c|c|c|}
\hline Variable & Category & Mean (S.D.)/N (\%) \\
\hline Age (in yrs) & & $26.61(6.30)$ \\
\hline \multirow[t]{2}{*}{ Gender } & Female & $141(62.7 \%)$ \\
\hline & Male & $84(37.3 \%)$ \\
\hline \multirow[t]{4}{*}{ Qualification } & Interns & $101(44.9 \%)$ \\
\hline & PG students & $80(35.6 \%)$ \\
\hline & BDS faculty & $8(3.6 \%)$ \\
\hline & MDS faculty & $36(16 \%)$ \\
\hline BMI $\left(\mathrm{kg} / \mathrm{m}^{2}\right)$ & & $23.61(5.11)$ \\
\hline \multirow[t]{4}{*}{ BMI } & Underweight & $18(8 \%)$ \\
\hline & Normal & $127(56.4 \%)$ \\
\hline & $\begin{array}{l}\text { Preobese/ } \\
\text { Overweight }\end{array}$ & $59(26.2 \%)$ \\
\hline & Obese & $21(9.3 \%)$ \\
\hline Average daily working hours & & $7.83(1.46)$ \\
\hline \multirow[t]{2}{*}{ Medical Illness } & Yes & $24(10.7 \%)$ \\
\hline & No & $201(89.3 \%)$ \\
\hline \multirow[t]{2}{*}{ Diet } & Vegetarian & $66(29.3 \%)$ \\
\hline & Non-vegetarian & 159 (70.7\%) \\
\hline \multirow{2}{*}{$\begin{array}{l}\text { Physical activity (sports/ } \\
\text { exercise/yoga) }\end{array}$} & Yes & $154(68.4 \%)$ \\
\hline & No & $71(31.6 \%)$ \\
\hline \multirow{2}{*}{$\begin{array}{l}\text { Recreational activity } \\
\text { (cycling, biking, hiking, camp- } \\
\text { ing, rock climbing, etc.) }\end{array}$} & Yes & 35 \\
\hline & No & 190 \\
\hline \multirow{2}{*}{ Smoking } & Yes & $7(3.1 \%)$ \\
\hline & No & $218(96.9 \%)$ \\
\hline \multirow{2}{*}{ Alcoholism } & Yes & $12(5.3 \%)$ \\
\hline & No & $213(94.7 \%)$ \\
\hline
\end{tabular}

Table 2: Self-reported job risk factors (\%)

\begin{tabular}{ll}
\hline Job risk factor & Major problem \\
\hline Performing the same task over and over & $33.3 \%$ \\
Treating an excessive number of patients in one day & $16.9 \%$ \\
$\begin{array}{l}\text { Performing manual techniques (hand scaling, use of } \\
\text { hand files, etc.) }\end{array}$ & $35.8 \%$ \\
$\begin{array}{l}\text { Not enough rest breaks or pauses during the } \\
\text { workday }\end{array}$ & $21.3 \%$ \\
Working in awkward and cramped positions & $45.8 \%$ \\
Working in the same positions & $38.9 \%$ \\
Bending or twisting your back/neck in an awkward & $43.6 \%$ \\
way & \\
Working near or at your physical limits & $26.4 \%$ \\
Reaching or working away from your body & $24.7 \%$ \\
Continuing to work while injured or hurt & $16.4 \%$ \\
Working with confused or agitated patients & $16.9 \%$ \\
Work scheduling overtime & $16.9 \%$ \\
Inadequate training on injury prevention & $13.8 \%$ \\
\hline
\end{tabular}

from neck pain $(48.9 \%)$ followed by lower back pain $(46.2 \%)$ and shoulder pain (45.8\%) (Table 3). Thirty-eight percent participants reported upper back pain (Table 3). About $43.5 \%$ participants reported symptoms in different body parts in the last 7 days. Among all the symptoms, lower back pain was highest (17.78\%) followed by neck pain and shoulder pain (16.89\% each) (Table 3$)$. 
Table 3: Distribution of musculoskeletal symptoms among different body parts (\%)

\begin{tabular}{lll}
\hline Body part & $\begin{array}{l}\text { \% Affected } \\
\text { (last 12 months) }\end{array}$ & $\begin{array}{l}\text { \% Affected } \\
\text { (last 7 days) }\end{array}$ \\
\hline Neck & 48.9 & 16.89 \\
Shoulder & 45.8 & 16.89 \\
Upper back & 38.2 & 14.67 \\
Elbows & 17.3 & 6.67 \\
Wrist/Hand & 10.7 & 10.67 \\
Lower back & 46.2 & 17.78 \\
Hips/Thighs & 16.4 & 7.11 \\
Knees & 19.1 & 7.11 \\
Ankle/Feet & 5.8 & 5.78 \\
\hline
\end{tabular}

Table 4: Predictors of MSDs among dental professionals

\begin{tabular}{llcc}
\hline Predictor & Category & OR & $95 \% \mathrm{Cl}$ \\
\hline Age & Less than 30 years/ & 1.766 & $0.737-4.233$ \\
& More than 30 years & & \\
Gender & Females/Males & 0.711 & $0.372-1.358$ \\
Diet & Non-vegetarian/ & 1.317 & $0.636-2.726$ \\
& vegetarian & & \\
Physical activity & No/Yes & 1.109 & $0.562-2.188$ \\
Recreational activity & No/Yes & 3.310 & $0.968-11.323$ \\
Smoking habit & No/Yes & 1.649 & $0.194-14.037$ \\
Alcoholism & No/Yes & 3.114 & $0.392-24.745$ \\
ADWH & Less than 8 hrs/ & 0.231 & $0.053-1.008$ \\
& More than 8 hrs & & \\
\hline
\end{tabular}

OR, odds ratio; $95 \% \mathrm{Cl}, 95 \%$ confidence interval

Regression analysis was performed to evaluate the risk factors of MSDs. All the variables showed statistically non-significant association with MSDs. Risk of developing musculoskeletal symptoms was more $(\mathrm{OR}=1.766)$ among those aged more than 30 years than those ages less than 30 years. Males showed less risk of developing MSDs as compared to females $(\mathrm{OR}=0.711)$. Vegetarians showed more risk $(O R=1.317)$ of developing MSDs as compared to non-vegetarians. Those who are not involved in regular physical activity showed more risk of developing MSDs (OR =1.109). Those who are not involved in recreational activity showed three times more risk of developing MSDs $(O R=3.310)$. Smoking $(O R=1.649)$ and alcoholism $(O R=3.114)$ were also contributing factors for development of MSDs (Table 4).

\section{Discussion}

The present study found that females are more prone to MSDs when compared to males. Many previous studies have supported the same findings. $2,6,9,12$ Physiological and anatomical differences in men and women coupled with effect of hormones on bones and connective tissues and decreased total muscle cross-sectional area may play a role. Strenuous physical work with higher psychosocial stress was found in female dentists which may contribute to higher prevalence of MSDs among women. ${ }^{13,14}$ A study by Alexopoulos et al. stated that female dentists associated with MSDs perceived $\mathrm{bad} /$ moderate health with increase in morbidity and chronic complaints in response to age.$^{15}$ In the present study, risk of developing musculoskeletal symptoms was $(O R=0.711)$ less among males as compared to females. On the contrary, a recent study by
Alyahya et al. states that female dentists had better awareness in ergonomics when compared to their male counterparts. ${ }^{5}$

It was also found that vegetarians showed more risk of developing MSDs as compared to non-vegetarians. However, a study conducted by Rayman and Pattison stated that fraction of patients following a vegetarian or Mediterranean-type diet experienced benefit in clinical symptoms. ${ }^{16}$ This benefit of vegetarian diet can be attributed to the high number of anti-oxidants obtained from various plant foods to combat oxidative stress during chronic inflammation but its role in acute WMSDs remains questionable. ${ }^{16}$ To our knowledge, no study has been conducted to investigate the relationship of diet with that of WMSDs. Dentists usually avoid physical exercise and activities due to exhaustion and fatigue, caused by heavy workload and long working hours. ${ }^{17,18}$ Present study showed that those who were not involved in regular physical and recreational activity showed more risk of developing MSDs. This is consistent with previous findings $s^{6,18-20}$ but is contrasting results were noted by Yasobant et al. ${ }^{2}$ Routine physical activity has shown to maintain and improve muscle tone, improve posture, increase in flexibility of joints and blood supply to various parts of body. ${ }^{11}$ Available literature shows the importance of physical activity as a preventive ergonomic measure. Aerobic exercises increase the flow of oxygen to tissues, thereby increasing efficiency. Stretching exercise is an effective measure for relaxing and reducing muscle tension caused by improper posture. ${ }^{11}$ Smoking and alcoholism are the other important predicting factors for MSDs. The plausible reason for this is that alcohol drinking and smoking are common health risk behaviors that might weaken body's normal functioning capacities and defense mechanisms. More possible explanation is that alcohol drinking might influence behavior of the people that often prohibits them from practicing a healthy lifestyle.

In the present survey, participants mostly suffered from neck pain (48.9\%) followed by lower back pain $(46.2 \%)$ and shoulder pain (45.8\%). These areas may correspond to the burdening of the spine at work. Dentists usually attain an awkward posture while sitting as well as standing with their head bent excessively and their body in uncomfortable position with their lumbar spine twisted in unnatural postures. The marked prevalence of shoulder pain among dentists can be explained by the fact that while working, the shoulders are often burdened during the extended periods of arm elevation and leaning forward in sitting or standing positions. ${ }^{21,22}$ Similar findings were seen in a research conducted on a group of dental practitioners. ${ }^{23,24}$ A study done by Al-Wassan et al. showed that the occurrence of neck pain was significantly higher among dentists than other oral healthcare professionals and $84 \%$ of oral healthcare workers flexed their neck while working. ${ }^{25}$ An EMG study of muscle activity during dental operating procedures was done by Finsen et al. which found that protracted neck flexion and shoulder abduction along with increased muscle activity with upper trapezius and splenius were seen on the working side. ${ }^{26}$

Working in an awkward position, bending or twisting back or neck, performing same tasks over and over again, performing manual tasks such as hand scaling, using manual techniques during root canal procedures, etc. were some of the self-reported job risk factors for MSDs in the present study. Awkward postures exert excessive force on joints and overload the muscles and tendons around the affected joint. Joints of the body are most efficient when they operate closest to the mid-range motion of the joint. Risk of MSD is increased when joints are worked outside of this mid-range repetitively or for sustained periods of time without adequate recovery time. Available literature states specific factors 
which pose a definite risk of causing MSD are prolonged static posture, long operating periods, handling of delicate instruments with significant force, reduced inter appointment breaks causing fatigue and micro injuries, etc. ${ }^{20,27,28}$ A recent study by Kumar et al. has suggested that prolonged muscle tension caused by incorrect posture can be relieved by stretching exercises. ${ }^{21}$ In the present study it was found that oral healthcare workers who work for more than 8 hours daily affected more $(86.7 \%)$ than those who work for less than 8 hours a day (77.4\%). A study done by Alyahya et al. has found that in the initial years of the practice, dental practitioners often work over 8 hours a day leading to early occurrence of MSD within 3 years. ${ }^{5}$ Also, it was found that professionals working at institutional setting as well as clinical setting had higher rates of MSD. ${ }^{2}$ Kierklo et al. stated that constant workings without breaks are associated with musculoskeletal discomfort. ${ }^{29}$ Thus, taking rest breaks with casual exercises between patients is imperative to reduce the incidence MSD.

Even though it is evident that regular exercise is of exceptional importance to the musculoskeletal health, only about two-thirds of respondents exercised regularly. The percentage of respondents who were utilizing alternative methods such as massages, spas or sports activities was even lower (16\%). Besides the high percentage of musculoskeletal complaints among respondents, only $16.88 \%$ sought professional help, which comes as a result either from the respondent's carelessness or the frivolous approach to this issue. High number of musculoskeletal problems should alert the practitioners and make actively concerned about their early diagnosis and treatment.

Dental institutes are training grounds for future dentists. Throughout the preclinical curriculum, special emphasis should be given on following the right posture and techniques. Short breaks between patients should be encouraged to allow for stretching exercises and a time limit should be established for treating a particular case. The benefit of this approach is twofold, it limits static postures thus reducing fatigue and helps patients from developing potential TMJ problems from excessive mouth opening for longer periods. As with any health hazard, prevention is better than cure. Dental colleges should address this issues by conducting periodic workshops with a team of dentists, physiotherapists and dietitians to sensitize the students the implications of poor posture in their professional career, promote physical activities, and encourage a healthy lifestyle.

The study was cross-sectional in nature and has its own limitations such as the representativeness of the sample and the ability of respondents to give correct answers. Small sample size and the use of one study area to recruit the participant's limits the results of the study in terms of generalizability. A larger sample size would achieve more comprehensive results. Dentists working in and around Sangli district should be included in future research investigations on MSDs. Study incorporated a structured questionnaire to collect the data. Questionnaire inquiry is an economical and proper way of collecting the data, but it can lead to recall bias. Perhaps more accurate results would require thorough physical examinations and assessments.

\section{Conclusion}

This study suggests that MSDs represent a serious burden on dental professionals. Hence, it becomes necessary for the dentists to identify appropriate risk factors and focus on appropriate preventive interventions that can help to reduce the prevalence of these problems. Present study involved student participants who reported musculoskeletal symptoms. It is need of the hour that the education regarding of ergonomic principles should begin early on, beginning with students of dentistry, and should be practiced throughout the life of a working dentist.

\section{References}

1. Zakerjafari HR, Yektakooshali MH. Work-related musculoskeletal disorders in Iranian dentists: a systematic review and meta-analysis. Saf Health Work 2018;9(1):1-9. DOI: 10.1016/j.shaw.2017.06.006

2. Yasobant S, Rajkumar P. Work-related musculoskeletal disorders among health care professionals: a cross-sectional assessment of risk factors in a tertiary hospital, India. Indian J Occup Environ Med 2014;18(2):75. DOI: 10.4103/0019-5278.146896

3. Bernard BP (Ed). Musculoskeletal Disorders and Workplace Factors A Critical Review of Epidemiologic Evidence for Work-related Musculoskeletal Disorders of the Neck, Upper Extremity, and Low Back. Cincinnati: DHHS (NIOSH) Publication 1997.

4. Bedi HS, Moon NJ, Bhatia V, et al. Evaluation of musculoskeletal disorders in dentists and application of DMAIC technique to improve the ergonomics at dental clinics and meta-analysis of literature. J Clin Diagnostic Res 2015;9(6):ZC01-ZC03. DOI: 10.7860/JCDR/2015/14041.6126

5. Alyahya F, Algarzaie K, Alsubeh Y, et al. Awareness of ergonomics \& work-related musculoskeletal disorders among dental professionals and students in Riyadh, Saudi Arabia. J Phys Ther Sci 2018;30(6):770-776. DOI: 10.1589/jpts.30.770

6. Jahanimoghadam F, Horri A, Hasheminejad N, et al. Ergonomic evaluation of dental professionals as determined by rapid entire body assessment method in 2014. J Dent (Shiraz, Iran) 2018;19(2):155-158.

7. De Sio S, Traversini V, Rinaldo F, et al. Ergonomic risk and preventive measures of musculoskeletal disorders in the dentistry environment: an umbrella review. PeerJ 2018;6:e4154. DOI: 10.7717/peerj.4154

8. Gupta G, Gupta A, Mohammed T, et al. Ergonomics in dentistry. Int J Clin Pediatr Dent 2014;7(1):30-34. DOI: 10.5005/jp-journals-10005-1229

9. Ayers KMS, Thomson WM, Newton JT, et al. Self-reported occupational health of general dental practitioners. Occup Med (Chic III) 2009;59(3):142-148. DOI: 10.1093/occmed/kqp004

10. Kahri P. Ergonomics and teamwork in dental treatment. Planmeca. Planmeca Oy: Published online 2005; p.12.

11. Nutalapati R, Gaddipati R, Chitta H, et al. Ergonomics in dentistry and the prevention of musculoskeletal disorders in dentists. Internet J Occup Health 2012;1(1):1-9.

12. Hayes MJ, Smith DR, Cockrell D. An international review of musculoskeletal disorders in the dental hygiene profession. Int Dent J 2010;60(5):343-352. DOI: 10.1922/IDJ_2514Hayes10

13. Lindfors $P$, Von Thiele $U$, Lundberg $U$. Work characteristics and upper extremity disorders in female dental health workers. J Occup Health 2006;48(3):192-197. DOI: 10.1539/joh.48.192

14. Mcclure SK, Adams JE, Dahm DL. Common musculoskeletal disorders in women. Mayo Clin Proc 2009;80(6):796-802. DOI: 10.1016/S00256196(11)61534-6

15. Alexopoulos EC, Stathi I-C, Charizani F. Prevalence of Musculoskeletal Disorders in Dentists 2004.

16. Rayman MP, Pattison DJ. Dietary manipulation in musculoskeletal conditions. Best Pract Res Clin Rheumatol 2008;22(3):535-561. DOI: 10.1016/j.berh.2007.12.010

17. Gosavi SS, Gosavi SY, Jawade RS. Posturedontics: reducing the stress in dentistry. World J Dent. 2012;3(4):335-339. DOI: 10.5005/jp-journals-10015-1185

18. Thakar S, Shivlingesh K, Jayaprakash K, et al. High levels of physical inactivity amongst dental professionals: a questionnaire based cross sectional study. J Clin Diagnostic Res 2015;9(1):43-46. DOI: 10.7860/JCDR/2015/10459.5466

19. Ballard C, Mobley W, Hardy J, et al. Dementia in Down's syndrome. Lancet Neurol 2016;15(6):622-636. DOI: 10.1016/S14744422(16)00063-6

20. Harutunian K, Gargallo-Albiol J, Figueiredo R, et al. Ergonomics and musculoskeletal pain among postgraduate students and 
faculty members of the School of Dentistry of the University of Barcelona (Spain). A cross-sectional study. Med Oral Patol Oral Cir Bucal 2011;16(3):425-429. DOI: 10.4317/medoral.16.e425

21. Kumar DK, Rathan N, Mohan S, et al. Exercise prescriptions to prevent musculoskeletal disorders in dentists. J Clin Diagn Res 2014;8(7):ZE13-ZE16. DOI: 10.7860/JCDR/2014/7549.4620

22. Hodacova L, Sustova Z, Cermakova E, et al. Self-reported risk factors related to the most frequent musculoskeletal complaints among Czech dentists. Ind Health 2015;53(1):48-55. DOI: 10.2486/indhealth.2013-0141

23. Rendžova $\mathrm{V}$, Apostolska S, Eftimoska $\mathrm{M}$, et al. Work related muskuloskeletal disorders among dentists at the university dental clinic in Skopje. Serbian Dent J 2018;65(2):89-96. DOI: 10.2478/sdj-2018-0009

24. Aljanakh M, Shaikh S, Siddiqui AA, et al. Prevalence of musculoskeletal disorders among dentists in the Ha'il Region of Saudi Arabia. Ann Saudi Med 2015;35(6):456-461. DOI: 10.5144/0256-4947.2015.456
25. AIWazzan KA, Almas K, Al Shethri SE, et al. Back \& neck problems among dentists and dental auxiliaries. J Contemp Dent Pract 2001;2(3):17-30. DOI: 10.5005/jcdp-2-3-1

26. Finsen L, Christensen H, Bakke M. Musculoskeletal disorders among dentists and variation in dental work. Appl Ergon 1998;29(2):119-125. DOI: 10.1016/s0003-6870(97)00017-3

27. Yamalik N. Musculoskeletal disorders (msds) and dental practice Part 2. Risk factors for dentistry, magnitude of the problem, prevention, and dental ergonomics. Int Dent J 2007;57(1):45-54. DOI: $10.1111 / j .1875-595 x .2007 . t b 00117 . x$

28. Morse T, Bruneau H, Dussetschleger J. Musculoskeletal disorders of the neck and shoulder in the dental professions. Work 2010;35(4):419-429. DOI: 10.3233/WOR-2010-0979

29. Kierklo A, Kobus A, Jaworska M, et al. Work-related musculoskeletal disorders among dentists - a questionnaire survey. Ann Agric Environ Med 2011;18(1):79-84. 